\section{Drug design centred}

\section{J.M. Midgley}

Quantitative Structure-Activity

Relationships in Pharmacology, Chemistry and Biology.

Editors Joachim K. Seydel and F.

Darvas.

Verlag Chemie. 4/yr. DM 280, \$168.

THE elaboration of molecules which will selectively control biochemical processes in a predictable manner is one of the ultimate goals of drug research. Drug design has been defined as the application of rational methodologies which result in a new drug (either through total innovation or via the optimization of a lead compound), and in the past two decades there has been a rapid development in techniques for elucidating quantitative structure-activity relationships (QSAR) for many compounds possessing diverse biological activities.

An indication of the activity in this field is the emergence of a specialist journal, $Q S A R$ in Pharmacology, Chemistry and Biology, which has a distinguished editorial staff drawn largely from academia in Europe and the United States. The purpose of the journal is "to collect contributions on all aspects of the subject embodied in its title", in particular theoretical and methodological aspects and innovative applications of QSAR. Each of

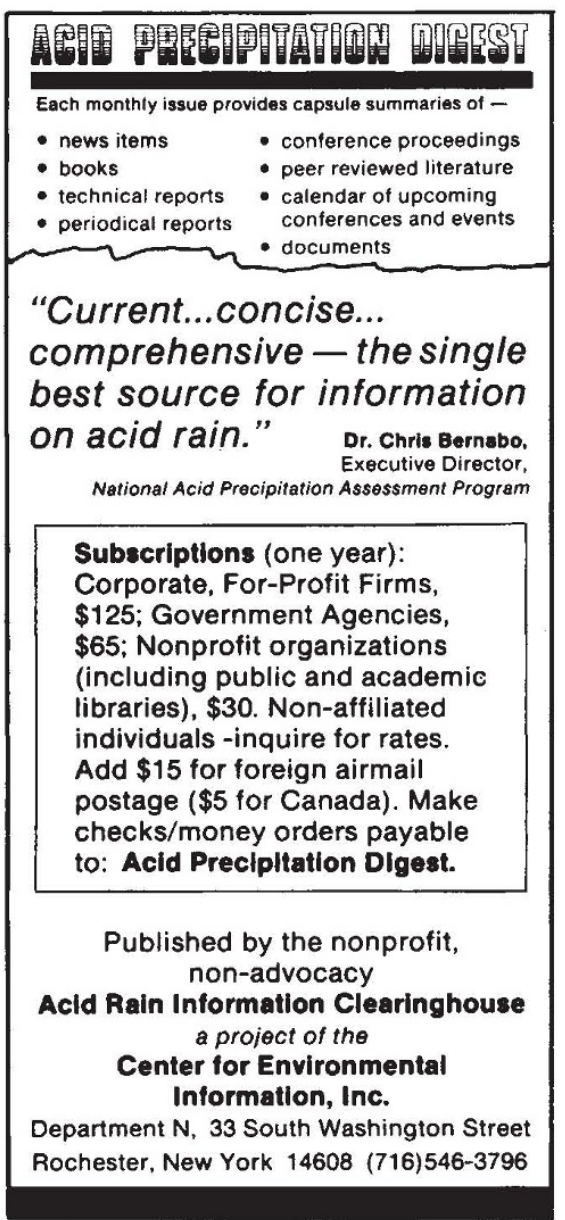

Circle No.34 on Reader Service Card. the four issues published annually contains about four refereed contributions (averaging five to six pages in length) of original research, and a balance of subject matter within the editorial remit has been achieved so far. The articles are clear and succinct, and their scientific standard is comparable to those of a similar nature appearing in established journals. The papers largely originate from Europe and the United States, and the significant industrial contribution reflects the growing economic (as well as scientific) importance of QSAR.

Somewhat surprisingly, there is no editorial comment or opportunity for correspondence and the remainder of each issue is taken up with approximately 60 abstracts of publications related to QSAR; these are comprehensive and drawn from diverse sources, but may be too dated to excite the aficionado. The whole is produced in a modern two-column format, with clear print and illustrations.

At the price the circulation may be confined to libraries and dedicated investigators in the field. The period from receipt to publication of the articles is variable, often only comparable to that in established international journals, so that research workers may opt to present their more interesting findings to a wider readership rather than preach to the converted. $\square$

J.M. Midgley is Professor of Pharmacy and Head of the Pharmaceutical Chemistry Division, Department of Pharmacy, University of Strathclyde.

\section{Picture chemistry!}

\section{Peter Kollman}

Journal of Molecular Graphics.

Editor A.J. Morffew.

Butterworth. 4/yr. £55, \$110.

THE Journal of Molecular Graphics (JMG), published in association with the Molecular Graphics Society, was founded to give "computational scientists" a forum to publish their work. The importance of computer graphics in studies of molecular systems, in drug design and in X-ray crystallographic studies of macromolecular structure has begun to be appreciated by many chemists. Indeed I am among the converts to the view that computer graphics is an essential tool for any chemist studying even moderately complex molecules. A corollary to this is that well-written computer software is often crucial in asking the most pertinent questions about a particular molecular system, and in answering them. Thus, there should be mechanisms for publication of software approaches to the solution of chemical problems and for giving due credit to elegant software.

In this context, it should be noted that
Computers and Chemistry (launched in 1976) and the Journal of Computational Chemistry (which first appeared in 1980 and was reviewed in Nature 299, 513; 1982) are journals where descriptions of both computer software and its applications are already welcomed. Of these two, it is significant that the latter has been the more successful because it has attracted a mix of software descriptions and applications of high quality and interest to many scientists.

In its first four issues, JMG has published articles mainly on computer graphics

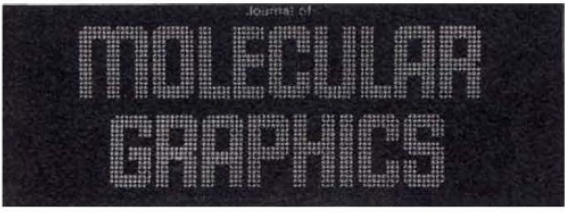

algorithms. Sample applications of the algorithms often occupy a small part at the end of the article and typically the papers do not have a strong scientific punch-line. One cannot blame the authors for saving their scientific message for journals where more chemical scientists will read them, but in my opinion the separation of computer graphics from other areas of computational chemistry is not a good idea. Besides the regular articles, the journal has also included a bibliography of molecular graphics applications, abstracts from the meetings which include computer graphics, and descriptions of new computer products of potential interest to chemists.

One commendable advance made by JMG is to combine colour figures from the individual articles into a central section of colour, thus allowing high-quality colour pictures to be published without charge to the authors. The science itself can often be delivered most effectively with colour figures, yet most journals charge a large amount for publication $(\$ 1,000-\$ 2,500$ by the Journal of Medicinal Chemistry, Journal of the American Chemical Society or Proceedings of the National Academy of Sciences) and often also require colourseparated prints (for example the Journal of Computational Chemistry).

The appearance of this journal has certainly facilitated the publication of articies dealing with computer graphics, particularly in the approaches requiring examples in colour. Whether it will thrive will depend on many factors, principally whether the field of molecular graphics will emerge as a separate discipline or whether the journal can attract articles which appeal not only to the molecular graphics community but to a broader constituency of chemists. How the focus could be broadened is not clear, but the very title of the journal cannot help but give the impression that papers other than those dealing explicitly with graphics are less likely to be accepted or receive a wide readership.

Peter Kollman is Professor of Pharmaceutical Chemistry in the School of Pharmacy University of California at San Francisco. 